\title{
Is Asprosin, A Real Actor of Diabetes Etiopathology?
}

\author{
Kader Ugur ${ }^{1}$, Meltem Yardim² and Suleyman Aydin² \\ ${ }^{1}$ Department of Internal Medicine, Endocrine and Metabolic Diseases, Faculty of Medicine, Firat University, Elazig, Turkey \\ ${ }^{2}$ Department of Biochemistry and Clinical Biochemistry, School of Medicine, Firat University, Elazig, Turkey
}

${ }^{*}$ Corresponding author: Dr. Suleyman Aydin, Department of Biochemistry and Clinical Biochemistry, School of Medicine, Firat University, 23119Elazig, Turkey, Tel: 905334934643, Fax: 904242379138; E-mail: saydin1@hotmail.com

Received date: May 10, 2018, Accepted date: May 19, 2018, Published date: May 21, 2018

Citation: Ugur K, Yardim M, Aydin S (2018) Is Asprosin, A Real Actor of Diabetes Etiopathology?. J Clin Mol Endocrinol 3:2.

Copyright: (C) 2018 Ugur K, et al. This is an open access article distributed under the terms of the Creative Commons Attribution License, which permits unrestricted use, distribution, and reproduction in any medium, provided the original author and source are credited.

\section{Editorial}

Diabetes mellitus is a metabolic disease, which occurs in combination with the genealogical and environmental factors and manifests itself with the extremely increase of the blood glucose level (hyperglycemia) [1]. If the mechanisms underlying of the diabetes are made evident as immediate as possible, it shall protect its place in the agenda as a serious public health problem of the present-day and future. Because the diabetes is a disease, which causes to the heart disease, paralysis, blindness, renal insufficiency and loss of limb, and affects one out of every eleven around the world [2,3]. There are already 5 different types of diabetes disease including Type 1 diabetes (insulindependent), Type 2 diabetes (insensitivity to the insulin hormone), maturity onset diabetes (the diabetes coming to existence in the early age and resembling to the Type 2 diabetes), Latent Autoimmune Diabetes in Adults (the condition coming to existence in the old age and resembling to the Type 1 diabetes and gestational diabetes (the temporary diabetes coming to existence in the pregnancy period) [4]. Even though the basic common characteristic is characterized with the increase of the glucose amount in the blood due to the insufficiency of the insulin hormone or resistance development to the insulin hormone or coexistence of both conditions in these five types; the mechanisms underlying of each type are different. There are data with reference to the direct connection between the synthesis and release of these different diabetes types different peptide based hormones. For example: It had been stated that there was a direct relationship between the expression and secretion of the adipose derivative hormones such as adiponectin, leptin, ghrelin, nesfatin-1, tumor necrosis factor- $\alpha$ (TNF- $\alpha)$, resistin, visfatin, irisin and etc. and diabetes [5-8].

In recent years, a new adipokine, which is released from the adipose tissue, had been explored by Romere et al. and researchers called this adipokine as "Asprosin". The Asprosin is a hormone separated from the C-terminal part of the profibrillin. This hormone is regulated with the starvation, circulated in the nanomolar levels and causes to the hepatic glucose release rapidly by activating the $G$ protein-CAMP-PKA way in the liver. It was reported that the Asprosin levels increased in the animals and human beings, which have the insulin resistance [9].
Moreover, while the Asprosin levels increase when the glucose amounts decrease, it decreases when the glucose amounts increase (Ex: With the nutrition) [10].

Carbohydrate metabolism is important in the development of type 2 diabetes and obesity. Therefore, we recently proposed "Do Gamma knife and cautery have a place in obesity treatment in future?" which means that it might have more of an immediate impact on blood sugar, so that not only controlling diabetes but also obesity in the near future.

In the view of such information, it is inevitable for the diabetes to play a role in all types of the Asprosin. As it is known, in case where the blood sugar may not be brought under control, the renal damage occurs in the microvascular level in the diabetic persons; in other words, the nephropathy develops, and this conditions is one of the frequent encountered reasons of the end-stage renal insufficiency. The Diabetic Nephropathy develops in the frequency of $20-30 \%$ in Type 1 DM and $10-20 \%$ in Type 2 DM, respectively. Likewise, the diabetic retinopathy comes to existence depending on the diabetes. As the disease progresses, the abnormal new vascularizations occur in the retina surface and cause to the blindness $[11,12]$.

The hepatical production of the glucose in an uncontrolled manner causes to the hyperglycemia undoubtedly. But, the glucose homeostasis is under control very tight to eliminate the damages that shall come to existence due to the glucose excess and shortage in the biological systems. In other words, regardless how much Asprosin causes the glucose formation in the liver; it shall try to keep the blood sugar level in the physiological limits by making the insulin production in the beta cells of the pancreas. However; nonproduction of the insulin or produced insulin resistance development and contribution of the Asprosin to the excessive glucose formation or glucose release increment by the glucagon cause to the problems in the pathological conditions.

Considering all this information, as the Asprosin is a glycogenic hormone [9], it may be one of the basic hormones underlying in the etiopathology of all the diabetes types and retinopathy and nephropathy syndromes developed depending on the diabetes $[11,12]$. It is even likely that it may be one of the reasons underlying of the short stature, too. Because, as the 
excessive production of the Asprosin causes to the excessive amount of glucose formation [9] and high glucose amounts suppress the growth hormone, short stature had been able to come to existence. It may be also used for the determination of the growth hormone in the future, because of this characteristic of it. Likewise, in addition to the excessive insulin release as the reason of the hypoglycemic attacks seen after the meals, it had been able to be resulted from not contributing of the Asprosin to the glucose formation in the liver or it may be resulted from inadequate production. Thus, the glucose had been able to decrease in the circulation.

In the future, the Anti-sprosin or Asprosin shall be able to be used as the therapeutic agent in the treatments of all the aforesaid diseases. Thus, the conditions coming to existence such as overeating, feeling of not being full, frequent need to urinate, mouth dryness, feeling of sweetness, drinking plenty of water demand, blurred vision, rapid and involuntary weight loss drying and itching on skin, feeling of weakness and fatigue, smell formation in mouth like acetone, discomforts like numbness and tingling in feet and formation of wounds later than normal shall disappear.

\section{References}

1. Rojas J, Bermudez V, Palmar J, Martínez MS, Olivar LC, et al. (2018) Pancreatic beta cell death: Novel potential mechanisms in diabetes therapy. J Diabetes Res 2018: 9601801.

2. Strain WD, Paldanius PM (2018) Diabetes, cardiovascular disease and the microcirculation. Cardiovasc Diabetol 17: 57.

3. (2017) Diabetes and your eyes, heart, nerves, feet and kidneys. National Kidney Foundation, New York, NY.
4. Ahlqvist $E$, Storm $P$, Karajamaki $A$, Martinell $M$, Dorkhan $M$, et al. (2018) Novel subgroups of adult-onset diabetes and their association with outcomes: A data-driven cluster analysis of six variables. Lancet Diabetes Endocrinol 6: 361-369.

5. Takahashi T (2010) Toward molecular neuroeconomics of obesity. Med Hypotheses 75: 393-396.

6. Joung KE, Park KH, Zaichenko L, Sahin-Efe A, Thakkar B, et al. (2014) Early life adversity is associated with elevated levels of circulating leptin, irisin, and decreased levels of adiponectin in midlife adults. J Clin Endocrinol Metab 99: E1055-E1060.

7. Bonfante ILP, Chacon-Mikahil MPT, Brunelli DT, Gáspari AF, Duft RG, et al. (2017) Obese with higher FNDC5/Irisin levels have a better metabolic profile, lower lipopolysaccharide levels and Type 2 diabetes risk. Arch Endocrinol Metab 61: 524-533.

8. Cha JJ, Min HS, Kim K, Lee MJ, Lee MH, et al. (2018) Long-term study of the association of adipokines and glucose variability with diabetic complications. Korean J Intern Med 33: 367-382.

9. Romere C, Duerrschmid C, Bournat J, Constable $\mathrm{P}$, Jain $\mathrm{M}$, et al. (2016) Asprosin, a fasting induced glucogenic protein hormone. Cell 165: 566-579.

10. Zhang L, Chen C, Zhou N, Fu Y, Cheng X (2017) Circulating asprosin concentrations are increased in Type 2 diabetes mellitus and independently associated with fasting glucose and triglyceride. Clin Chim Acta 17: 30430-30438.

11. Gheith O, Farouk N, Nampoory N, Halim MA, Al-Otaibi T (2016) Diabetic kidney disease: Worldwide difference of prevalence and risk factors. J Nephropharmacol 5: 49-56.

12. Raman R, Gella L, Srinivasan S, Sharma T (2016) Diabetic retinopathy: An epidemic at home and around the world Indian J Ophthalmol 64: 69-75. 